\title{
Mak Nyahs and Sex Reassignment Surgery - A Qualitative Study from Pahang, Malaysia
}

\author{
Draman $S^{a}$, Maliya $S^{a}$, Syaffiq $M^{a}$, Hamizah $Z^{a}$, Abdul Hakim $A^{a}$, MR Razman ${ }^{b}$ \\ aDepartment of Family Medicine, Kulliyyah of Medicine, International Islamic University Malaysia Kuantan, \\ Pahang. \\ bepartment of Community Medicine, Kulliyyah of Medicine, International Islamic University Malaysia, \\ Kuantan, Pahang.
}

\section{ABSTRACT}

Introduction: Mak nyahs are locally known male-to-female transgenders in Malaysia. In Western countries, medicalization of transgenderism allows strictly selected patients to undergo sex reassignment surgery. However, a standardized treatment system is not yet available in Malaysia. A number of mak nyahs underwent sex reassignment surgery at their own will. This study aimed to explore mak nyahs' knowledge and perception on sex reassignment surgery. Materials and Methods: A qualitative research was carried out from $13^{\text {th }}$ July 2016 till 31st August 2016 among 8 adult mak nyahs in Kuantan, Pahang. Snowball sampling was used. Participants who gave verbal consent were interviewed individually and in focus groups. Data obtained was transcribed and used as the primary data source. Results: All informants were Malays and Muslims. They generally had some knowledge about the standard procedures and risks in sex reassignment surgery. All informants expressed their desire to have the surgery, but chose not to. Reasons discouraging them from having the surgery were: i) religion, ii) forbiddance from family, iii) fear of regret, iv) death from surgery, and v) the lack of necessity. Factors driving them to have the surgery: i) more income from sex work, ii) pressure from sex clients, iii) securing a stable relationship, iv) self-satisfaction, and v) hope for a better future. Conclusion: Religion seemed to be the main reason refraining them from undertaking the surgery. Counselling mak nyahs should include the advantages and disadvantages of sexual reassignment surgery. Islamic religious preaching is very important to help reduce high risk behaviours, as well as teaching mak nyahs to cope with challenges in adult life. Further research is necessary to show association between religious knowledge and successful rehabilitation of the mak nyahs' community.

KEYWORDS : Mak nyah, male-to-female transgender, sex reassignment surgery.

\section{INTRODUCTION}

\section{Transgenderism and sex reassignment surgery}

Transgenders are individuals who transiently or persistently identify with a gender different from their natal gender. Transsexuals are individuals who seek, or have undergone a social transition from male to female (or female to male). Sometimes, this transition also involves a somatic change by cross-sex hormone treatment and genital surgery (sex reassignment surgery). ${ }^{1}$

Corresponding Author

Assoc. Prof. Dr Samsul Draman

Department of Family Medicine

Kulliyyah of Medicine

25200 Kuantan, Pahang

Tel : +6013-9827277 (hp) +609-5704572 (tel)

Email : nurin@iium.edu.my
Management of male-to-female transgenderism generally includes psychiatric assessment, cross-sex hormonal treatment, and sex reassignment surgery. The main procedures in sex reassignment surgery usually include orchidectomy, penectomy, clitoroplasty, labiaplasty, and neovaginoplasty (creation of the neovagina). Other common surgeries to enhance the female secondary sexual characteristics and improving aesthetic appearance include breast augmentation, facial feminization surgery, permanent hair removal, lipoplasty, and feminization laryngoplasty. ${ }^{2,3}$

\section{Transgenders in Malaysia}

In Malaysia, male-to-female transgenders are known as mak nyahs in the local language. ${ }^{4}$ It was estimated that there are at least 50,000 mak nyahs in Malaysia. ${ }^{5}$ Majority of mak nyahs in Malaysia are 
Malays (about 80\%) and also are Muslims. ${ }^{6,7}$

Mak nyahs are a well-known community in the Southeast Asian culture and history, especially in Malaysia. Before 1983, mak nyahs were allowed to seek sex reassignment surgery and change their gender on the national identification cards. However, in 1983 the Malaysian Conference of Rulers issued a ban against sex reassignment surgery for Muslims which includes mak nyahs (however, hermaphrodites were given exception). ${ }^{8}$

Literatures from worldwide reported that transgenders generally face discriminations in education, employment, and healthcare settings due to their gender expression. They also suffer from violence, and are also being criminalized in many countries. ${ }^{9}$ Mak nyahs in Malaysia, like transgenders all over the world, are being marginalized from the local society as well. ${ }^{6}$

Sex trade has been a common means of income for the mak nyahs. It has been reported that $86.6 \%$ of mak nyahs in Malaysia are sex workers. ${ }^{4}$ This is because they are often not able to find and secure proper employment due to social discrimination, thus rendering them to facing economic vulnerability..$^{6,9,10}$ Involvement in the sex trade exposes the mak nyahs as well as the general public to HIV infection and sexually transmitted diseases. The high rate of involvement in the sex trade also worsens the social stigma onto the mak nyah community. ${ }^{10}$

Due to the social discrimination, mak nyahs have also been afraid to seek medical help. In addition, healthcare providers in Malaysia also lack the knowledge on health issues specifically faced by mak nyahs. Therefore, many crucial steps in managing transgenderism have been neglected by the professionals. For instance, most of the time procedures such as taking cross-sex hormones are self-prescribed with no supervision and monitoring from the healthcare providers. ${ }^{6,10}$

Documentations related to mak nyahs and sex reassignment surgery in Malaysia are scarce. Most authors only discussed the political issues concerning the banning of sex reassignment surgery among mak nyahs. This study main objective was to document the mak nyahs' knowledge on sex reassignment surgery. We also aimed to understand factors that encourage and discourage the mak nyah community towards sex reassignment surgery, and to explore the extent of religious influence towards the mak nyahs decision in sex reassignment surgery.

\section{Materials and methods}

A qualitative study was done, where semistructured, in-depth interviews were carried out in the forms of groups and individuals. There were 8 informants. They were identified by a contact person who was a mak nyah. The research proposal and protocol were approved by the International Islamic University Malaysia Research Ethics Committee (IREC 455). All 8 informants understood and were willing to participate in the study. They were all mak nyahs living in Malaysia, above 18 years old, and could communicate in Bahasa Malaysia.

Two focus group discussions consisting of 2 and 3 informants separately, were carried out on two separate days respectively. The informants were interviewed individually within each focus group, while the other subjects were allowed to add in explanations whenever necessary. The sessions were conducted in a private, isolated room at the Primary Care Clinic, International Islamic University Malaysia, Kuantan campus. Another 3 informants were interviewed individually on separate days in their residential areas and work places. All interview sessions were conducted between $13^{\text {th }}$ July 2016 and $31^{\text {st }}$ August 2016. All informants were interviewed in Bahasa Malaysia and verbal consent taken before interview started. Three researchers were involved in the interview sessions: as an interviewer, a scriber, and a manager of the recording systems. Their roles were the same in all sessions.

Seven domains were discussed: i) personal information covering socio-demographic profile, ii) family relationship, iii) life background as a transgender, iv) faith and religious background, v) knowledge about sex reassignment surgery, vi) factors encouraging sex reassignment surgery, and vii) factors discouraging. Every informant was asked all questions, and was encouraged to provide further information for discussions.

Each session lasted for about one and a half hours. It was recorded with the informant's permission, 
from start to finish, with two video and audio cameras as well as a voice recorder for backup purpose.

ATLAS.ti version 7.5.7 software was used for data processing and analysis. The recordings were transcribed manually by the three researchers cum authors involved in the interview. Relevant nonverbal communication data (e.g. body gestures, pitch and tone of voice, interpersonal space, etc.) by the informants were included in the transcript as well. The transcript was then verified twice by the authors against the recordings, and was then used as the primary data source. Two cycles of coding were done. No new theme was derived.

Verbatim quotes were used in this study to assist in describing the findings. They were translated into English by one of the authors, who was also an experienced translator familiar with both Bahasa Malaysia and English linguistic cultures.

\section{RESULTS}

i) Socio-demographic profile

All informants lived in Kuantan. They were of Malay ethnicity and Muslims. Every one of them had a female alias. Their age ranged from 19 to 54 years old. Majority of them at least completed secondary education. Their monthly income was about MYR1,000 to MYR2,000. Three of them were full time sex workers, 2 were part time sex workers, while the remaining 3 had already quit the sex trade. A brief socio-demographic profile of the 8 informants is described in Table 1. Quotes in the sections below were given numbers according to the informants.

\section{ii) Family relationship}

The relationship between the informants and their family members varied. Some informants had close family ties, while some informants came from broken families. They all had many siblings, ranging from 5 to 8 siblings per family.

\section{iii) Life background as a transgenders}

All informants mentioned that they started to feel the differences between their gender identity and birth sex since childhood. They generally displayed more feminine characteristics and behaviours since early age. They preferred female playmates and feminine play activities, and even tried on female clothing and make-ups. A few of them disclosed that because of their feminine character, they were bullied and sexually assaulted when they were

Table 1 Socio-demographic profile of the informants

\begin{tabular}{|c|c|c|c|c|c|c|c|}
\hline $\begin{array}{l}\text { Informant } \\
\text { ID }\end{array}$ & Birth place & & Age & Marital status & $\begin{array}{l}\text { Education } \\
\text { level }\end{array}$ & Occupation & $\begin{array}{l}\text { Monthly } \\
\text { income } \\
\text { (MYR) }\end{array}$ \\
\hline R1 & $\begin{array}{l}\text { Pahang, } \\
\text { Malaysia }\end{array}$ & & 19 & Single & $\begin{array}{l}\text { Completed } \\
\text { secondary } \\
\text { education }\end{array}$ & Sex worker & Uncertain \\
\hline $\mathrm{R} 2$ & $\begin{array}{l}\text { Jakarta, } \\
\text { nesia }\end{array}$ & Indo- & 23 & Single & Diploma & $\begin{array}{l}\text { Beauty and fashion, } \\
\text { part time sex worker }\end{array}$ & 1000 \\
\hline R3 & Malaysia & & 54 & Single & $\begin{array}{l}\text { Completed } \\
\text { secondary } \\
\text { education }\end{array}$ & $\begin{array}{l}\text { Food peddler } \\
\text { (former sex worker) }\end{array}$ & Uncertain \\
\hline R4 & Malaysia & & 51 & Single & $\begin{array}{l}\text { Completed } \\
\text { secondary } \\
\text { education }\end{array}$ & $\begin{array}{l}\text { Tailor } \\
\text { (former sex worker) }\end{array}$ & 1000 \\
\hline R5 & Malaysia & & 53 & $\begin{array}{l}\text { Married, has } \\
\text { one adopted } \\
\text { child }\end{array}$ & $\begin{array}{l}\text { Completed } \\
\text { secondary } \\
\text { education }\end{array}$ & $\begin{array}{l}\text { Officer in govern- } \\
\text { ment sector } \\
\text { (former sex worker) }\end{array}$ & 2000 \\
\hline R6 & $\begin{array}{l}\text { Pahang, } \\
\text { laysia }\end{array}$ & Ma- & 18 & Single & $\begin{array}{l}\text { Completed } \\
\text { secondary } \\
\text { education }\end{array}$ & Sex worker & Uncertain \\
\hline R7 & $\begin{array}{l}\text { Pahang, } \\
\text { Malaysia }\end{array}$ & & 30 & Single & Degree holder & $\begin{array}{l}\text { Entertainment, part } \\
\text { time sex worker }\end{array}$ & $\begin{array}{l}\text { Uncertain, } \\
\text { but can be } \\
\text { up to } 10,000\end{array}$ \\
\hline R8 & $\begin{array}{l}\text { Kelantan, } \\
\text { Malaysia }\end{array}$ & & 39 & Single & Primary school & Sex worker & 1000 \\
\hline
\end{tabular}


children. However, the details were not probed further regarding the sexual assault cases.

The mak nyah community plays a significant role in gathering younger mak nyahs and teaching them how to transition. The community is also responsible for recruiting these mak nyah youths into the sex trade. Mak nyahs usually gathered in lorong at late night. Lorong is a Malay word for small alley; but to suit the context, it refers to dark and hidden places such as backstreets, and carries a negative meaning when used colloquially. ${ }^{11}$ In this study, the informants generally started taking sex-hormones and working in the sex trade at a tender age of 14 to 23 years old.

Despite the society's negative attitude towards the mak nyah community, the informants had accepting families. Some families set limits to how far the informants could transition, while others were accepting towards their transgender lifestyle.

"In my family, everyone is okay with me. I would wear like this - all woman's attire, woman's clothes, except that I don't put on makeup. And I don't think my parents would mind if I undergo sex reassignment surgery. But they have emphasized to me, if the surgery is not that important, then there is really no necessity to proceed."

- R\#8

"My mother said to me, it's alright if I remain this way (living as a mak nyah), I can have bigger breasts, but I must not remove my male genitals. My mother strongly disapproves that."

- R\#1

However, most of the families were not aware of the informants' involvement in sex trade. One informant mentioned that his family was tolerant with his mak nyah lifestyle, but was against his job as a sex worker.

Employment was not a challenge for some of the informants. They were able to work with the general public with minimal conflicts, as long as they followed the rules and regulations of the work place. Entering or quitting the sex trade was sometimes merely a personal choice.

"I was a lecturer in a university, teaching information technology. But I stopped half way, because I couldn't continue anymore. I wanted to pursue beauty instead. So I just quit my job, and straightaway.... (entered the sex trade)." - R\#7

"I became aware of myself. We'll never know who we will end up as, right? I had a friend, his life taught me great lessons. This friend committed suicide. He had HIV, and he was stressed out, he couldn't bear with his life anymore. And then I started to think. Am I going to live my life like this forever? A life without aims, without vision. So I became a government servant. As government servants, we have to be aware of our boundaries. We cannot have long hair. We have to be disciplined."

- R\#5

iv) Faith and religion practices

All informants were Muslims from birth. They received Islamic religious teachings from their parents and religious teachers since childhood. One informant was from an officially established religious school.

The informants reported that they had stopped practicing religious rituals (i.e. daily prayers and recitation of the Holy Quran) when they started the transition as mak nyah and began to work as sex workers. Mak nyahs who stopped trading sex or had decent jobs resumed religious practices and performed religious rituals on a daily basis. All informants were aware that in Islam, the methods which Muslims practice religious teachings and perform religious rituals are according to their birth sex.

"The way I pray should follow the males. But I no longer pray. I only go for Quran recitation sessions."

- R\#6

Most of them were willing to receive religious teachings and resume religious practices again. However, a few informants who were still sex workers described that they faced discriminations when they wanted to enter the mosque.

"There was once, I wanted to pray at the mosque. I had to dress like a male because I had to dress according to my birth sex in my religion. But then people in the mosque were like, 'Can mak nyahs enter the mosque?!' And since then I have never 
been to any mosque."

- R\#7

The informants agreed that they would be more enthusiastic to attend Islamic religious programs if the preachers were non-discriminating, more open and 'mak nyah-friendly'.

"If they (religious preachers) don't force us to change drastically, it should be acceptable. I mean, their approach is sometimes very forceful, it won't help us improve, we will just become more rebellious. If there are preachers who could use a more gentle approach, we won't go against the teachings."

- R\#2

v) Knowledge about the procedure

All informants did not undergo sex reassignment surgery. Although they had wished for the surgery, they were determined not to undergo sex reassignment surgery in the future. In this section, the informants narrated their knowledge and attitude about sex reassignment surgery.

All informants have heard about sex reassignment surgery and were aware of the legal, psychiatric, medical, and surgical processes involved in a successful sex reassignment. The informants learned about sex reassignment surgery from discussions with their friends and information shared by their friends on social media.

In most cases, mak nyahs would go to Singapore and Thailand to have the sex reassignment surgery. The cost varies from MYR8,000 to MYR18,000. The higher the cost of the surgery, the more favourable the outcome would be. However, ethical concerns remained behind these surgical procedures as there have been frequent undesirable outcomes. Surgeries performed especially in Thailand had no pre-operative assessment. Sadly, most mak nyahs would often skip the post-operative follow up sessions.

"In Thailand, you come today, you tell the doctor, 'I want to operate tomorrow.' Tomorrow he will perform the operation. He won't ask you anything unlike a psychiatrist who will ask you all sorts of questions - no he won't. You just need to have money. This is why there are so many transsexuals in Malaysia. In the past, it was easy for them to get money, they went there (Thailand) there was no expert to evaluate you. You present to the doctor, you'll get operated immediately."

- R\#3

vi) Factors encouraging sex reassignment surgery

Discrimination from the general public renders mak nyahs to turn to their other mak nyah peers for support and assistance. Therefore, mak nyahs form highly coherent communities, especially mak nyah sex workers. When a mak nyah chooses to have sex reassignment surgery, peers and environmental influences would usually be the leading reasons. Specific factors were discussed below:

\section{a) Pressure from customers}

Majority of the mak nyah community were sex workers. Although their customers would usually ask for anal sex, oral sex, and masturbation, many other customers would be willing to pay more for exotic sexual experience with a mak nyah that had a neovagina.

"Some of the customers are very evil. A lot of them would influence the mak nyahs to undergo operation. A customer will come to the groups of mak nyahs (sex workers), suddenly he asks, 'I want an operated one, do you have any?' or 'I want a vagina.' Sometimes it feels very heart-breaking. If you want a vagina, you could have just approach the female prostitutes over there. You come here to find mak nyahs, all of a sudden you want a vagina. This makes some of the mak nyahs want to have sex reassignment operation... (During a sex trade session) we gather together in a big group, the customer will ask each of us 'Have you had an operation?' or 'Who among you has had an operation?' And he is willing to give us tips! 'And then he'll be like.... 'Thank you very much kid, I want to take that one because that one had operation.' So it makes us feel frustrated, 'I will have an operation too!'”

- R\#3

"Yeah customers can be a factor too. When we have undergone the operation, there is no need for us to negotiate with the customers. We just mention the price, we decide the price."

- R\#6

b) Money and higher social status

Mak nyahs, especially sex workers, usually come 
from families of low socioeconomic status. Therefore, they would use all possible means, including sex reassignment surgery, to obtain more income as well as higher social status among their peers.

"One night we can earn some money. At least we could get one or two (customers). One customer is MYR50. Umm, the operated ones will be MYR70 to $80 .$. I do think that my friends went for the operation because they want to earn more money." - R\#8

(Interviewer asked, “Are those who have undergone the surgery better than other mak nyahs?")

"Of course! Because (the operated mak nyahs) have 'that thing' (neovagina). So as to say, they are wealthier. They are more popular now, and are prouder of who they are."

- R\#6

It was easy for the mak nyahs to save enough money for a trip to go for the surgery. Sometimes, mak nyahs were even able to undergo the surgery for free.

\section{c) Self-satisfaction and self-fulfilment}

Sex reassignment surgery also permitted the mak nyahs to own a body resembling that of the 'perfect women', since it resolved the mental conflict between their gender identity and anatomical sex.

"I witnessed my friend underwent the operation. He is my best friend. He told me about his desire to have sex reassignment. He said he wanted to become a real woman, he wanted to be accepted (by the society) as a woman."

- R\#4

d) Hoping for a better life

For other mak nyahs who wanted to have a better life in the future, they viewed sex reassignment surgery as the stepping stone to a new self or a new chapter of life. After the surgery, some of them were able to escape the sex worker community and migrate to places that were more open and accepting towards transgenders.

\section{e) Seeking a stable relationship}

Sex reassignment surgery was considered a means to establish stable relationships with male partner. Although in Malaysia it is not legal for a mak nyah to marry a man, this community usually refers a stable, intimate male partner as a 'husband'. To mak nyahs, sex reassignment surgery is needed to emphasize their role as the woman or wife, so to show their commitment in the relationship.

"We stay in the lorong also because we want to be loved. We need attention, we need to find men who could understand our life. This is one of the reasons why we work in lorong, not just to work for money. We want men who would take care of us. If there are men who would want to look after us, we would straightaway go for the operation."

- R\#3

vii) Factors discouraging sex reassignment surgery All informants admitted that although they had the desire to have sex reassignment surgery, they choose not to have it. The reasons these mak nyahs refused sex reassignment surgery were not mutually exclusive. But generally, their choice could because of the following reasons:

\section{a) Deemed unnecessary}

Some informants felt that sex reassignment surgery was simply unnecessary. They observed no obvious improvement in lifestyle among their mak nyah peers who have undergone the surgery. Therefore they chose not to face the risks of the surgery.

"I have thought about it. I thought about what is the real purpose of having this sex reassignment surgery. I feel that, if this is the purpose of our life, then there is no end to it (seeking pleasure). So I think I won't need this... When I look at my friends who have been operated, they are not living a happier life either...."

- R\#4

Some informants observed that sex reassignment surgery would cause the mak nyahs to miss out many opportunities in their sex life, especially in sex trade. In addition, many customers were not able to afford more expensive and exotic sex services.

"I won't have the operation. I don't feel that the operation will make me have more income. The operated ones will have fewer customers. So it's the same... Customers nowadays want all kinds of services. When they see us (who have not undergone operation), sometimes they want to suck our penis, they want us to penetrate them, we will 
charge them another range of prices, we could increase the price. So it will be a loss if we have the operation done... Sometimes the customer will request to have an operated one (mak nyah sex worker). When they do their business in the room, all they did was sucking the customer's penis. Sometimes the customers won't even choose the operated ones. They are very expensive." - R\#8

\section{b) Concerns about the future}

Some of the informants expressed their concerns about their future if they choose to proceed with sex reassignment surgery. They expressed their openness towards the uncertainties and unexpected possibilities in the future, and therefore did not want to undergo the surgery.

"I don't want to have a permanent change. We don't know what will happen in the future." - R\#2

\section{c) Religion}

All informants were aware that Islamic religious rulings do not allow Muslims to alter their birth sex. From their narrations, it was clear that religious prohibition was one of the main reasons they chose not to have the surgery. One of the practical reasons mentioned by informants is because having the surgery would create confusion in performing religious rituals. The informants were also fearful of the sinful nature of the surgery, and that God would not forgive them in afterlife.

"After we die, the effect (of the operation) still remains. Our identity cards still say we are males. So after we die, when our body undergoes the religious cleansing bath, people will look at our body, they will be confused whether this body belongs to a male or a female. When I thought about death, I cancelled the plan."

- R\#7

"When we think about the future, let's say, in the future, we want to reverse (back to original birth sex), and repent from our sins... I do think about my religion, think about myself. The surgery would make me commit sins. In afterlife, I will suffer. I will suffer even in my grave. In Islam, this surgery is forbidden. At least I know this."

- R\#8
In addition, the informants believed that, although they could enjoy a luxurious life in this world, they should still observe their limits, because eventually as they age, they will have to focus on working on their afterlife. Besides, holding onto religious believes could guide the mak nyahs out from living negative lifestyle. The mak nyahs would interpret drastic events in life as signs of calling from God. The repented informants in this study were grateful that having religious faith within themselves led them towards new directions in life. Living according to religious guidance gave the informants a sense of peace and belonging, a purpose of living, and a more positive feeling about themselves, and they wished the same for other mak nyahs.

The informants also reported that mak nyahs who did not receive much religious teachings in childhood were more likely to choose sex reassignment surgery, and were more unwilling to seek religious guidance.

"If we tell them (the operated mak nyahs) about religion, about what is permitted, what is prohibited, about death, they quickly argue back. Why they argue is because they know they couldn't follow our advice anymore. They feel that they have gone too far."

- R\#3

\section{d) Family}

In Malaysia, people emphasize immensely on family values, since family values have been essential in Islamic teachings. The children often believed that parents would always know better, since the parents were always more experienced in life. Advices and opinions from the parents were always highly respected, even when the children have become adults. For mak nyahs, who were often rejected by the society, parents were often their strongest source of love and support. Therefore, words from their parents were often obeyed unconditionally.

"(I did not undergo the surgery) just because of one single thing: my parents told me not to. They told me, if it's not necessary, then don't do it. Although they don't seem to mind if I do it, but yes I take their advice seriously." - R\#8 


\section{e) Regret}

All informants reported that regret was very common among mak nyahs who had sex reassignment surgery. The mak nyahs may experience a euphoric phase after sex reassignment surgery. However, as the mak nyah got older, he would lose his beauty, and his appearance would no longer be appreciated. Although the exact statistics could not be determined in this current study, cases of regret seemed so common that the informants were fearful towards sex reassignment surgery.

“He wouldn't lower his ego, he feels regretful, but he won't (admit), although we could see his feelings on his face, he regrets about him removing the genital. Maybe when he was younger he followed his desires too much, he wanted too much to become a woman, now that he is older, he wants to return back, but his physical condition has already changed, he doesn't know where he stands now, how he should pray, where he should pray, etc. Compared to us, who haven't changed, our genitals still remain, we have the confidence, but those (post-operation mak nyah) don't have the confidence anymore."

- R\#3

"If you ask me, I do not agree (with sex reassignment surgery). Especially those who underwent this operation at a younger age. Because from my observation and experience, many of them will regret. The regret comes as one gets older. (When they are still young) they are still fresh, they are still beautiful, they will get carried away. Being pampered by so much money, and having a perfect husband. It's all fun. But eventually everything will collapse. A lot of them will regret. The regret comes when they are older."

- R\#2

"I've heard some stories. Some do regret. After they had the surgery for a long time, they would start to feel regret. Usually after many, many years. It would be too late for them to reverse." - R\#8

Another reason of regret is reduced sexual satisfaction after the surgery. Some mak nyahs found this extremely distressing, and even experience mental disturbances.
"At the early stage, they have problem with sexual stimulation, because they tend to experience less sexual stimulation after the operation. As time goes by, they become depressed, thus later on they will have psychological problem as they could no longer achieve sexual pleasure."

- R\#3

\section{f) Death}

One of the common concerns about sex reassignment surgery was death. As mentioned above, there were many places that offered sex reassignment surgery for the sake of obtaining profit, and therefore practiced unethical services to the mak nyahs.

"We have thought about death. If the operation is not successful, we are going to die in a foreign land."

- R\#7

\section{DISCUSSION}

Limitations of the study should be mentioned prior to discussing the findings. Although a sample size of 8 informants was adequate for a qualitative study, ${ }^{12}$ this research was descriptive in nature, and the informants were recruited from Kuantan (a town in East Coast of Peninsular Malaysia), therefore it does not represent the entire mak nyah community in Malaysia.

However, findings from this qualitative study could still provide significant insight on mak nyahs' knowledge and perception on sex reassignment surgery, as well as the influence of religious belief on the mak nyahs' views about their life. This study too highlights the inadequacy of education on health risks faced by the mak nyah community.

The mak nyah community is a very cohesive community, where members of the community are often in close contact with each other. They rely heavily on other mak nyahs to obtain and share information, including information on medical and surgical practices. The influence of peer pressure is powerful. Professionals are needed to educate this community with the correct and culture-relevant knowledge, so that members could distribute the correct information in the community. 
Male-to-female sex reassignment surgery is difficult, complex and risky. Optimal surgical management in sex reassignment surgery requires a multidisciplinary approach with a team of dedicated physicians. ${ }^{2}$ Although efforts are being made by the Malaysian Ministry of Health to manage health issues in the mak nyah community, ${ }^{13}$ a standardized and conveniently available treatment system as well as experienced health practitioners for mak nyah patients are yet to exist in Malaysia. ${ }^{10}$

\section{Transitioning to the opposite gender}

According to the description of the informants in this study, the process of transitioning and the decision towards sex reassignment surgery among mak nyahs are very similar to those in Thailand. Kathoeys (Thai: male-to-female transgenders) in Thailand also follow the advices from the senior members of their kathoey community when it comes to using feminizing hormones and deciding for sex reassignment surgery. ${ }^{14}$

In Thailand, where many of the Malaysian mak nyahs would go to for the surgery, the healthcare system does not cover all aspects of the transitioning process, since there are not enough experienced psychiatrists and endocrinologists to manage transgender patients. ${ }^{14}$ Besides, psychiatric evaluations were assumed to be unnecessary for kathoeys who have been taking hormones on a selfprescription basis. Therefore, transgenders from other countries, including mak nyahs, do not have to undergo psychiatric evaluation either. ${ }^{15}$ In addition, the duration of follow up is inadequate for mak nyahs who chose to change their sex in Thailand. Foreigners who come to Thailand for sex reassignment surgery are usually being followed up for two weeks, while for local kathoeys for one year. ${ }^{14}$ Due to the short duration of follow up for post-surgery mak nyahs, their post-surgery quality of life has been neglected. Thus, long-term complications and psychological distress are expected to be common in these individuals.

Sex reassignment surgery - the ultimate decision The decision of sex reassignment surgery is heavy, since the outcome is irreversible. The informants in this study chose not to undergo the procedure because of many factors, not just merely due to religious reasons only, as suggested by Teh in $2001 .{ }^{8}$ Even in Thailand, where kathoeys are well accepted by the local culture, religion, and general public, only $30 \%$ of them had the desire to undergo the surgery. ${ }^{15}$ In addition, many of the kathoeys in Thailand would eventually resume their life in a more masculine manner as they age, which is a phenomena similar to the sample of informants in this study. ${ }^{15}$

The availability of a committed male partner towards a stable, long-term relationship is a crucial factor for some mak nyahs to decide for sex reassignment surgery. However, mak nyahs are identified as males in the Malaysian legal system. The system does now allow a male to legally marry a mak nyah, so such relationship is not protected or supported by any law. ${ }^{10}$ Therefore, dissolution of the relationships could evoke devastating emotions to the mak nyahs, which could lead to disastrous consequences, such as regret and suicide.

The transgender (mak nyahs) patients in North America, Europe and Australia are carefully diagnosed with gender dysphoria and candidates for sex reassignments surgery are then meticulously assessed. ${ }^{2}$ Sadly mak nyahs in Malaysia would choose sex reassignment surgery for the sake of attracting more customers and better pay for sex services getting paid with better prices. ${ }^{10}$ Transgender sex workers who have undergone sex reassignment surgery are less likely to use condoms for receptive penetrative anal sex with their customers. ${ }^{16}$ Penetrative sexual actions are frequent in sex workers, making their neovaginal lining being exposed to mechanical (i.e., abrasion) and physiological (ie, accumulation of sebum and retained semen or lubricant) factors that could increase the risk of microtears. In addition, the granulation tissue formed after the surgery, which can persist after the initial healing period, is another biological risk to sexually transmitted diseases, including HIV. ${ }^{17}$

Suggestions of practical approach to tackle this issue include thorough pre-op assessment and counselling done by the primary health care provider and also by the multidisciplinary team that is going to be involved with the surgery.

Majority of mak nyahs in Malaysia are Malays and Muslims. Islam is a religion with rulings and rituals practiced differently by different genders. Therefore the natal gender is crucial in determining the 
method a Muslim practices his/her religion. When counselling a Muslim mak nyah who expresses his wish for sex reassignment surgery, the importance of his natal gender in relation to Islamic practices must be reminded and emphasized to the client. This would at least be a gesture of respect towards his faith. Findings in this study suggest that mak nyahs who did not undergo the sex reassignment surgery were more confident in practicing their religion. Thus, reminding the mak nyah about possible religious obligations in the future could also help in preventing regret and other possible psychological distress for the mak nyah individual.

Discrimination and marginalization from the society is merely one of the many reasons mak nyahs could not escape the sex trade. This study has provided narrative evidence that many customers were willing to pay high prices to the mak nyah sex workers requesting for a variety of sex services. Selling sex provides quick income with little hard work. Thus, mak nyah sex workers' involvement in the sex trade is also a result of the "supply and demand" vicious cycle.

Therefore, educating the mak nyah community is not enough. Efforts should be made to educate the general public too so that there would be a reduction in customers asking for sex services from mak nyahs. Education to the general public should not be just about teaching how to practice safe sex, rather people should be reminded more on abstinence from having sex with casual partners, having multiple sex partners, especially obtaining services from sex workers. In Islam, it is prohibited for Muslims to engage in any sexual activity outside the wedlock. ${ }^{18}$ Thus, strengthening religious awareness on sexual practices could be helpful for both mak nyahs and the general public to end sex trade.

If the demand is not suppressed, sex trade would always continue to thrive. Hence sexually transmitted diseases such as HIV will remain endemic in the country as a result of high risk and unsafe sexual practices.

Discrimination in employment against the transgender community has been discussed in many literatures around the world. In Malaysia, mak nyahs are discriminated in work places due to their appearance in transitioning. ${ }^{10}$
Based on the narrations in this study, employment does not seem to be a problem when the mak nyahs display agreeable attitude towards the rules and regulations in their work places. The senior informants in this study have stopped cross-dressing and has blended well in the society as masculine characters, and they work decent jobs as well. Dress code is an important determinant whether a mak nyah is willing to accept any job. ${ }^{10}$ Therefore, when counselling mak nyah sex workers into changing their lifestyle, persuading them to compromise and tolerate the dress codes is hoped to be helpful for them to quit sex trade and find better sources of income.

Sex reassignment surgery has been shown to be an effective and medically necessary treatment for patients with gender dysphoria after appropriate diagnosis and psychotherapy. ${ }^{23}$ Many of the techniques for male to female sex reassignment surgery have been proven to produce good functional and aesthetic outcomes. Modern surgical techniques include vaginoplasty allowing for coitus and the formation of a sensible neoclitoris for sexual orgasm. ${ }^{24}$ Furthermore, in a meta-analysis of five studies of 223 transgender women who underwent penile inversion vaginoplasty, a mean of $75 \%$ reported the ability to have vaginal intercourse $70 \%$ to $84 \%$ reported the ability to orgasm, $76 \%$ to $100 \%$ reported satisfaction with vaginal length. ${ }^{25}$

However, sex reassignment surgery can expose patients to complications depending on the surgical techniques. A meta-analysis of 26 studies which included over 1400 patients who underwent penile inversion vaginoplasty reported $12 \%$ to $33 \%$ wound dehiscence, $4.2 \%$ to $15 \%$ of stricture of the neovaginal introitus, an average of $7 \%$ of neovaginal stricture other than the introitus, $1 \%$ to $17 \%$ of rectovaginal fistula, $2 \%$ to $10 \%$ of vaginal shrinkage and $3 \%$ to $10 \%$ of surgical bleeding. ${ }^{25} 13$ male to female transsexuals were followed-up between 6 and 25 years, with the average of 12 years. Surgical outcome was disappointing and only one-third had a functioning vagina. ${ }^{26}$

A patient who has undergone the surgery from male to female, needs to seriously consider that the outcome is irreversible. It is not only physical but also psychological changes which might be difficult to cope with especially regret. There are postoperative complications that need to be 
considered too like scarring, heamatoma, infection, stricture and etc. ${ }^{26}$

They must continue taking cross-sex hormones in order to make them physically attractive and psychologically stable. Many studies have found that these hormones had complications like myocardial infarction, venous thrombosis and etc. ${ }^{27}$ Transsexual women also suffer from specific difficulties particularly sexual arousal, lubrication and dyspareunia. However they function well on a physical, emotional, psychological and social level. ${ }^{28}$ Another study found rates of hypoactives sexual desire are similar to those found in the general female population. They also had moderate to high rates of orgasmic functioning. ${ }^{29}$

Many studies from Malaysia argued that Islam alienates and stigmatizes the mak nyah community by emphasizing the prohibition of cross-dressing and feminizing medical/surgical procedures in the religion, and that the Malaysian religious authority has criminalized and discriminated cross-dressers in the country. ${ }^{6-8,10}$ However, despite discrimination and criminalization, the mak nyah community must not be denied of their rights to seek religious guidance.

Spirituality and religion have been proven to be successful in reducing the HIV-related risk behaviours in the younger transgender community. ${ }^{19,20}$ Since transgenders are at higher risk of suffering from mental illnesses, addiction problems and suicide; ${ }^{9}$ religiosity and spirituality play an important role in the process of recovering from mental illness as well as providing a protective function against addictive or suicidal behaviours. ${ }^{21}$ As these individuals age, they would face challenges and milestones of adulthood namely health concerns, changing family dynamics, and challenges associated with ageing. Thus they would need organized religious communities where they can fulfil their religious and spiritual needs. ${ }^{22}$

Since Islam is the birth religion of the Malay mak nyahs, they take the religion seriously, even though the mak nyahs may not strictly follow the religious rules and rituals in their daily lives. When stressful events occur, they would still try to practice rituals such as performing prayers, managing the deceased, and preparing for burial. Mak nyah sex workers who are conscious about their faith in Allah would often expect themselves to eventually quit the sex trade later on in life as they age. In all, the ultimate aim is to eliminate sex trace in order to help this community. Therefore, Islamic spiritual teachings and religious participation must be persistently encouraged in this community to instil the positive values of Islam, thus supporting them to leave their unhealthy, forbidden lifestyle.

Community-based religious preachers and Muslim healthcare professionals should also help in providing bio-psycho-socio-spiritual care for every mak nyah encountered. This way, it is hoped that all the challenges faced by mak nyah communities would be addressed in a more empathic and holistic manner.

\section{CONCLUSION}

Sex reassignment surgery is an irreversible procedure and could bring significant negative impacts in mak nyahs' life. However, some mak nyahs would still choose to have the surgery at their own wish. Sex reassignment surgery and anal sex among mak nyah sex workers could increase the risk of HIV transmission. In addition, IBBS survey found an alarming increasing trend in alcohol and psychotropic drugs used prior to having sex among transgenders with $38.1 \%$ and $22 \%$ using alcohol and drugs respectively in 2012 to $39.5 \%$ and $24.1 \%$ using alcohol and drugs respectively in 2014. These overlapping risks certainly impede the proper use of condom during sexual intercourse. ${ }^{4}$ Due to the lack of psychiatric assessment before surgery, regret is not uncommon among post-surgery mak nyahs. Many mak nyahs would not choose to do the surgery because of religious reasons, forbiddance from family, fear of regret, death from surgery, and the lack of necessity. However some would still want to have the surgery because i) they would earn more from sex work, ii) they feel pressure from their sex clients, iii) securing a stable relationship, iv) selfsatisfaction, and v) hoping that after the surgery they would have a better future. From western literature, transsexuals appear to have sexual satisfaction following sexual reassignment surgery. However majority of mak nyahs in Malaysia are Malays and Muslims, we suggest that spiritual intervention would be helpful in guiding the mak nyahs in making the correct choices in life, as well as helping them to cope with stressful life events. Further research needs to be done to prove that religion plays a major role to rehabilitate the mak 
nyahs.

Conflict of interest

The authors in this study declare that there is no conflict of interest. There is no registration with NMRR as no Ministry of Health facilities were used in this study. This is a self-funded study with no grant.

\section{ACKNOWLEDGEMENT}

We would like to express our immense gratitude to International Islamic University Malaysia (IIUM) for providing the resources for this study. We would also like to thank Amir Fadzli B. Mohd Zahid and the Department of Family Medicine in IIUM for lending their video recorders. Special gratitude is also expressed to Haziq Hussaini B Fauzi for assisting the research team in managing the sound recorder system during the interview sessions.

\section{REFERENCES}

1. DSM-V. American Psychiatric Association: Diagnostic and Statistical Manual of Mental Disorders, Fifth Edition. Arlington, VA, American Psychiatric Association.2013

2. Trombetta C, Liguori G, Bertolotto $M$. Management of Gender Dysphoria: A Multidisciplinary Approach:Springer;2015

3. Horbach SE, Bouman MB, Smit JM, et al. Outcome of Vaginoplasty in Male-to-Female Transgenders: A systematic review of surgical techniques. The Journey of Sexual Medicine.2015;12(6):1499-512

4. M.O.H. National Strategic Plan: Ending AIDS 2016-2030. Ministry of Health Malaysia, Putrajaya:2015

5. Ng E. Malay transsexual loses court bid to change gender Kuala Lumpur, Malaysia: Yahoo! News;2011 (cited $2016 \quad 27^{\text {th }}$ August ,2016) Available from: https://www.yahoo.com/ news/malay-transsexual-loses court bid change gender 053645639.html

6. Teh YK.HIV-related needs for safety among male-to-female transsesxuals (mak nyah) in Malaysia. SAHARA: Journal of Social Aspects of HIV/AIDS Research Alliance.2008;5(4):178-85

7. Wei CL, Baharuddin A, Abdullah R, Abdullah Z, Ern KPC. Transgenderism in Malaysia. Journal of Dharma.2012

8. Teh YK. Mak nyah (male transsexuals) in Malaysia: The influence of culture and religion on their identity. International Journal of Transgenderism.2001;5(3):97-03.

9. UNAIDS. The Gap Report. UNAIDS 2014

10. Gibson BA, Brown S-E, Rutledge R, et al. Gender identity, healthcare access and risk reduction among Malaysia's mak nyah community. Global Public Health.2016:1-16

11. Draman S, Soufeiya $M$, Mohd Rus $R$, et al. Psycho-social and spiritual backgrounds, experiences and needs as a transsexual: a qualitative study within Persatuan Insaf Pahang. International Medical Journal Malaysia ( IMJM).2016;15(2):27-36

12. Onwuegbuzie AJ, Dickinson WB, Leech NL, Zoran AG. A qualitative framework for collecting and analyzing data in focus group research. International Journal of Qualitative Methods.2009;8(3);1-21

13. Garis Panduan Pengendalian Masalah Kesihatan Gender di Klinik Kesihatan. First ed. Putrajaya Malaysia:Kementerian Kesihatan Malaysia ;2017

14. Chokrungvaranont $P$, Selvaggi $G$, Jindarak $S$, et al. The development of sex reassignment surgery in Thailand: a social perspective. The Scientific World Journal.2014.

15. Aizura AZ. Feminine transformations: Gender reassignment surgical tourism in Thailand. Medical anthropology.2010;29(4):424-43

16. Nemoto T, Iwamoto M, Perngparn U, et al. HIVrelated risk behaviours among kathoey (male-to -female trangender) sex workers in Bangkok, Thailand. AIDS care.2012;24 (2):210-9

17. Jarolim L, Sedy J, Schmidt M, et al. Gender reassignment surgery in male-to-female transsexualism: A retrospective 3-month follow up study with anatomical remarks. J Sex Med.2009;6(6):1635-44

18. The Holy Quran. Chapter 17 , verse 32 .

19. Golub SA, Walker JNJ, Longmire-Avital B, Bimbi DS, Parsons JT. The role of religiosity, social support and stress related growth in protecting against HIV risk among transgender women. Journal of health Psychology.2010;15(8):113544

20. Downshen $N$, Forke $C M$, Johnson $A K$, et al. Religiosity as a protective factor against HIV risk among young transgender women. Journal of Adolescent Health.2011;48 (4):410-4

21. Unterrainer HF, Lewis A, Fink A. Religious / spiritual well-being, personality and mental health: A review of results and conceptual issues. Journal of religion and health.2014;53 
(2):382-92

22. Halkitis PN, Mattis JS, Sahadath JK, et al. The meanings and manifestations of religion and spirituality among lesbian, gay, bisexual and transgender adults. Journal of Adult Development.2009;16(4):250-62

23. Cohen-Kettenis PT, Gooren LJ. Transsexualism: A review of etiology, diagnosis and treatment, J Psychosom Res, 46 (1999),pp 315-333

24. Karim RB, Hage JJ, Mulder JW. Neovaginoplasty in male transsexuals: A review of surgical techniques and recommendations regarding eligibility. Ann Plast Surg, 37 (1996),pp 669-675

25. Horbach SE, Bouman MB, Smit JM, et al. Outcome of Vaginoplasty in Male to Female Transgenders: A Systematic Review of Surgical Techniques. J Sex Med 2015; 12:1499.

26. Lindemalm, G., Körlin, D., \& Uddenberg, N. Long term follow up sex change in 13 male to female transsexuals. Archives of sexual behavior. Vol 15, No 3, 1986.

27. Sex change surgery guide: Pros Cons, side effects, scars and after care. Available at www.Medhalt.com.

28. Weyer $\mathrm{S}$, et al. Long-term assessment of the physical, mental and sexual health among transsexual women. J Sex Med.2009.

29. Klein $\mathrm{C}$, et al. Sexual functioning in transsexuals following hormone therapy and genital surgery: A review. J Sex Med 2009 
